\title{
AS CRIPTOMOEDAS COMO MERCADORIA-EQUIVALENTE ESPECÍFICA: UMA BREVE LEITURA DO FENÔMENO A PARTIR DA OBRA “O CAPITAL" DE KARL MARX
}

\section{THE CRIPTOCURRENCIES AS EQUIVALENT AND ESPECIFIC GOOD: A CONCISE READING ABOUT THE PHENOMENON BY KARL MARX'S THE CAPITAL}

\author{
Mauricio Antonio Tamer ${ }^{1}$
}

\begin{abstract}
RESUMO: Propóe uma nova leitura do fenômeno das criptomoedas com base na teoria de Karl Marx a colocada em sua obra "O Capital", precisamente a partir das ideias relacionadas às duas funçôes do ouro, ao dinheiro e à circulaçâo de mercadoria. Propóe, entấo, a possibilidade de ajuste conceitual das criptomoedas como mercadoriaequivalente específica.
\end{abstract}

PALAVRAS-CHAVE: Criptomoedas. Karl Marx. Mercadoria-equivalente específica.

\begin{abstract}
Try to establish a concise reading about the phenomenon of the cryptocurrencies from Karl Marx's theory placed in his book "The Capital", precisely from the ideas related with the two functions of the gold, the money and the movement of goods. Proposes, therefore, the possibility of conceptual adjustment of cryptocurrencies as equivalent and specific good.
\end{abstract}

KEYWORDS: Cryptocurrencies. Karl Marx. Equivalent and specific good.

\section{INTRODUÇÃO}

Esse trabalho tem por escopo tentar fazer uma leitura do fenômeno das criptomoedas a partir dos conceitos expostos por Karl Marx, mais precisamente uma leitura a partir da teoria posta no Capítulo 3 do Livro I de sua obra "O Capital", onde sấo colocadas as ideias das funçôes do ouro e do dinheiro na circulaçăo de mercadorias.

Para tanto, em um primeiro momento, o estudo ficará concentrado na compreensăo do que săo e como funcionam as criptomoedas, o que passa necessariamente pelo entendimento de como funciona o que é o blockchain, plataforma onde as criptomoedas se desenvolvem.

1 Doutorando em Direito Político e Econômico pela Universidade Presbiteriana Mackenzie - MACKENZIE. Mestre em Direito Processual Civil pela Pontifícia Universidade Católica de Sáo Paulo - PUC/SP. Graduado em Direito pela Universidade Presbiteriana Mackenzie de Sáo Paulo - MACKENZIE. Membro do Instituto Brasileiro de Direito Processual - IBDP. Professor em cursos de graduaçăo e pós-graduaçăo. Advogado. mauriciotamer@gmail.com 
Na sequência, o estudo se dedicará ao entendimento da caracterizaçăo das criptomoedas como mercadoria-equivalente específica.

Isso é possível pela compreensáo da teoria de Karl Marx onde esse reconhece uma dupla funçáo do ouro. Uma primeira representada por sua própria expressáo de valor, ou seja, o ouro como mercadoria em si considerada, e uma segunda funçăo de representar os valores das mercadorias, como uma grandeza de referência que viabiliza a circulaçâo.

Após, verificar-se-á que o fenômeno das criptomoedas se ajusta a essa teoria de Karl Marx como medida-equivalente específica porque assumem a qualidade de mercadorias em si consideradas, e porque assim o sâo, tem-se observado a aceitaçăo dessas como meios de pagamento.

\section{ENTENDIMENTO PRELIMINAR DO QUE SÃO E COMO FUNCIONAM AS CRIPTOMOEDAS}

A leitura do fenômeno das criptomoedas a partir dos conceitos colocados no capítulo 3 do livro I da obra "O Capital" de Karl Marx parece passar necessariamente de sua melhor compreensáo técnica. Isso se justifica nâo só do ponto de vista acadêmico e lógico, mas principalmente pela peculiaridade do tema e pela certa escassez de textos jurídicos a respeito. Assim, nesse primeiro ponto do ensaio, a ideia é tentar passar a compreensăo de como funcionam tecnicamente as criptomoedas.

Muito bem. Para tanto, é preciso compreender como premissa de raciocínio o que é o blockchain ${ }^{2}$, mecanismo tecnológico ou ambiente onde elas se desenvolvem. Mas o que é essa ferramenta? Em traduçăo livre, o termo em inglês blockchain significa cadeia de blocos, ideia que representa grande parte de sua essência estrutural.

Blockchain pode ser compreendido como uma rede descentralizada de terminais eletrônicos, na grande maioria computadores, distribuídos ao redor do mundo e interligados pela internet. É assim uma rede peer-to-peer ${ }^{3}$, em que cada usuário de forma voluntária disponibiliza seu dispositivo em prol dessa malha descentralizada de dispositivos. Cada dispositivo representa, portanto, a imagem de um nó ou um ponto de intersecçăo da rede.

Diferentemente do que pode ser chamada, para fins desse trabalho, de forma tradicional de armazenamento eletrônico de informaçôes, onde tais dados săo salvos e

2 Blockchain tem sido considerado a nova revoluçâo tecnológica: "One model of understanding the modern world is through computing paradigms, with a new paradigma arising on the order of one per decade. First, there were the mainframe and PC (personal computer) paradigms, and then the Internet revolutionized everything. Mobile and social networking was the most recent paradigm. The current emerging paradigma for this decade could be the connected world of computing relying on blockchain cryptography. [...] The economy that the blockchain enables is not merely the movement of money, however; it is the transfer of information and the effective allocation of resources that money has enabled in the humam - and corporate-scale economy." (SWAN, 2015, Preface XI).

3 A principal característica das redes peer-to-peer é a de que cada um dos dispositivos conectados nessa rede descentralizada é ao mesmo tempo um cliente ou receptor da informaçăo como um servidor da rede. Cada dispositivo, portanto, exerce essa dupla funçâo. Difere da rede mais comum em que há um servidor concentrando a emissâo da informaçáo e todos os demais dispositivos a ele conectados apenas funcionam como clientes ou receptores dessa informaçăo ou mensagem eletrônica. 
armazenados em dispositivos ou servidores centralizados (mesmo os serviços de cloud ou nuvem săo assim ${ }^{4}$ ), todas as informaçôes armazenadas ou transmitidas nessa rede (dados) năo estâo concentradas em um único dispositivo ou servidor, mas de forma compartilhada por todos e em todos dispositivos. E mais, cada um dos dispositivos ou nó dessa malha tem toda a cópia integral do blockchain. ${ }^{5}$

Exemplifica-se. Se você leitor, edita um arquivo de texto em seu computador, os dados a ele atrelados ficarăo armazenados no próprio HD de sua máquina, em um lugar só. Ou, você pode transferi-lo ou copiá-lo para um pen-drive, ou ainda, salvá-lo em um e-mail ou em algum serviço de nuvem, como os fornecidos pelas empresas Apple, Google e Microsoft. Nesses casos, os dados continuam registrados e salvos de forma centralizada seja em um dispositivo ou nos servidores de tais provedores de aplicaçăo. ${ }^{6}$

No blockchain, de forma diferente, o armazenamento das informaçōes se dá de forma descentralizada, ou seja, o arquivo, a transcriçâo ou a transaçâo realizada é registrada em toda a rede. Significa que o armazenamento se dá de forma pública e que cada terminal integrante dessa grande rede ou malha pode acessar imediatamente as informaçōes armazenadas? Exatamente, cada dispositivo, como dito, tem uma cópia fidedigna e validada das informaçôes de todo blockchain, funciona como uma grande livro-razăo de registro eletrônico de informaçōes. ${ }^{7}$

Além do armazenamento distribuído, o desenvolvimento ou a construçăo do blockchain se dá em blocos sequenciais ou em cadeia. Uma corrente de vários elos. É dessa característica estrutural que surge o nome da tecnologia e com base na qual, como se verá na sequência se desenvolvem as criptomoedas. E mais. Essa cadeia nâo é apenas uma questăo de forma, mas também de formataçâo e segurança do conteúdo nela contido.

4 Na computaçâo de nuvem ou cloud computing o armazenamento das informaçôes năo se dá no dispositivo do próprio usuário, mas nos servidores da empresa que presta o serviço, como Apple, Google e Microsoft. A ideia da nuvem é que essas informaçóes săo acessadas, mediante internet, de qualquer lugar. O usuário usa seu dispositivo, acessa à internet e recebe as informaçóes armazenadas no servidor dos provedores. Ainda assim o armazenamento é concentrado.

5 "The "Bitcoin core" software can be freely downloaded at https://bitcoin.org/en/choose-your-wallet. The standard Bitcoin implementation includes a number of features. Typically, it creates a "wallet" file for the user that can store bitcoins (without giving a name or proof of identity); it creates an individual node for the user in the peer-to-peer Bitcoin network that can be used with a standard Internet connection; and it provides access to the "block chain" data structure that verifies all past Bitcoin activity [...] Indeed, each individual bitcoin can readily be traced back through all transactions in which it was used, and thus to the start of its circulation. All Bitcoin transactions are readable by everyone in records stored in a widely replicated data structure. In general, transactions are ordered recursively by having the input of a transaction (roughly, the source of funds) refer to the output of a previous transaction. (For example, the transaction might reveal that Bob pays Charlie using bitcoin he received from Alice.)" (BÖHME, 2015, p. 215).

6 Provedor de aplicaçâo é qualquer provedor ou empresa que disponibilize alguma funcionalidade ao usuário já conectado à internet. Como bem define Rony Vainzof "qualquer serviço de Internet, excetuando os provedores backbones e os provedores de conexăo ou de acesso, seja pago, gratuito ou filantrópico, como redes sociais, portais de conteúdo, contas de e-mail, mensagens instantâneas e demais aplicativos, podem ser considerados como de aplicaçōes de Internet" (VAINZOF, 2014, p. 189).

7 Como diz Melanie Swan: "The blockchain is the public ledger of all Bitcoin transactions that ever been executed. It is constantly growing as miners add new blocks to it (every 10 minutes) to record the most recent transactions. The blocks ar added to the blockchain in a lienar, chronological order. Each ful node (i.e. every computer connected to the Bitcoin network using a cliente that performs the task of validating na relaying transactions) has a copy of the blockchain, which is downloadesd automatically when the miner joins the Bitcoin network." (Idem, Preface X). 
Explica-se. O segundo bloco contém a informaçâo do primeiro e do segundo bloco. O terceiro bloco contém a informaçăo do terceiro, mas também do primeiro e do segundo blocos. $\mathrm{O}$ quarto bloco, por sua vez, contém sua própria informaçâo e a dos outros três anteriores, e assim sucessivamente. Cada próximo bloco de informaçôes é criado a partir e com base em todas as informaçôes da cadeia de blocos anteriores e além disso confere validade a todas as informaçóes anteriores.

Assim, ilustrativamente a compreensăo do blockchain se dá a partir de duas imagens (i) uma primeira de perspectiva vertical ou sequencial de que há uma cadeia de blocos de informaçăo em que cada bloco contém sua informaçăo e de todos anteriores e (ii) uma segunda de perspectiva horizontal ou distributiva de que o blockchain está em uma malha descentralizada de dispositivos, em que cada dispositivo tem uma cópia fidedigna da cadeia de blocos.

Significa dizer que para apagar ou alterar uma informaçâo presente em algum dos blocos é necessário alterar todos os demais, mas năo só. Como o armazenamento se dá em malha descentralizada e cada um dos dispositivos ou nós dessa malha contém uma cópia simultânea e fidedigna, qualquer alteraçăo em qualquer um dos blocos precisa ser validada tecnicamente por todos os dispositivos da malha. Isso confere segurança ao sistema, pois é inefetivo um ataque em um só dos dispositivos, diferente da forma tradicional de armazenamento, e também afasta o risco de gasto-duplo da criptomoeda como será explicado na sequência. Para alguém vulnerabilizar o sistema, por exemplo, teria de ter a força técnica para destruir toda a rede descentralizada.

Além dessa segurança estrutural, por assim dizer, do sistema, o blockchain se utiliza de criptografia ${ }^{8}$ forte e consistente baseada na combinaçăo técnica de chaves privadas e públicas. ${ }^{9}$ Basicamente, para o que basta para entendimento desse trabalho, cada dispositivo (usuário) pertencente ao blockchain recebe uma chave privada para adicionar e alterar informaçôes na rede. Privada porque apenas o usuário possui essa chave. Inserida e validada na rede, para todos os demais usuários ela é tecnicamente convertida em uma chave pública à qual todos têm acesso e que confere a segurança de que aquele determinado usuário foi quem de fato tratou a informaçấo na rede. A chave pública é, por assim dizer, a face externa e validada pelo blockchain da chave privada, confirmando-a. ${ }^{10}$

80 termo criptografia surge da junçăo etimológica dos termos gregos kryptós (escondido) e gráphein (escrita) e significa o estudo de técnicas pelas quais a informaçấo pode ser transformada de sua forma original para uma forma ilegível, de modo que apenas o emissor da mensagem e o receptor da mensagem que compreendem a técnica de transformaçâao possam saber seu conteúdo. Na informática e principalmente no blockchain essas transformaçôes sâo feitas pela técnica de chaves privadas e públicas, mediante altas performances computacionais.

9 Chaves particulares e públicas podem ser compreendidas como sequências de letras e números tecnicamente elaborados e combinados por meios informáticos de alta complexidade. As particulares săo conferidas apenas ao usuário como uma espécie de senha pessoal. As públicas săo geradas a partir da inserçâo da informaçấo no blockchain pelo usuário. A chave pública, com a redundância explicativa, é a versăo pública da chave privada.

10 "A cryptographic hash function is similar to a regular hash function, but it should have some elements that make it useful in the cryptography context. One of them is the fact that whatever changes are made on the original data, even a very slight one, generates a very different". (ALBUQUERQUE, 2015, p. 6). 
Com toda essa estrutura descentralizada pública, de multiplicidade de cópias fidedignas e pela criptografia, ${ }^{11}$ inserida uma informaçâo no blockchain ela náo pode ser mais alterada, o que assegura sua validade e a confiabilidade de todo sistema, salvo de alguém tivesse condiçōes técnicas de vulnerabilizar toda rede ou se a internet năo mais existir no globo, situaçôes praticamente impossíveis.

Com essas características o blockchain é uma funcionalidade que pode ser utilizada para várias situaçóes em que é preciso a preservaçâo de algo em um ambiente digital, notadamente pelas vantagens econômicas e de segurança que o mecanismo apresenta. Assim, por exemplo, é possível pensarmos na preservaçăo em blockchain de algum conteúdo disponível na internet (similarmente do que é feito por ata notarial - art. 384 do Código de Processo Civil), desenvolvimento de smart contracts (contratos inteligentes), auxiliando cartórios na preservaçáo de seus registros, contribuindo com a maior eficiência nas açôes governamentais, ${ }^{12}$ viabilizando participaçâo popular na iniciativa de projetos de lei, ${ }^{13}$ para registro de reputaçăo de empresas ou negociadores. ${ }^{14}$ Enfim, existindo a necessidade de preservaçăo segura, mais rápida e econômica de qualquer informaçăo, o blockchain é um caminho viável.

E essa estrutura viabilizou a configuraçấo e nascimento das chamadas criptomoedas, que recebem esse nome justamente pela criptografia sobre a qual elas estâo baseadas, com maior destaque a principal delas conhecida como Bitcoin, mas muitas outras já existem com blockchains (redes) próprios e até com propósitos diferentes. ${ }^{15}$

11 "Cada blockchain, como o que usa Bitcoin, é distribuído: ele é executado em computadores fornecidos por voluntários ao redor do mundo; nâo há nenhuma base de dados central para hackear. O blockchain é público: qualquer pessoa pode vê-lo a qualquer momento, pois reside na rede e năo dentro de uma única instituiçăo encarregada de operaçôes de auditoria e manutençâo de registros. E é criptografado: ele usa criptografia pesada, envolvendo chaves públicas e privadas (semelhante ao sistema de duas chaves para acessar um caixa forte) para manter a segurança virtual.". (TAPSCOTT; TAPSCOTT, 2016, p. 36-37).

12 Na Estônia, por exemplo, há a iniciativa de integrar os serviços prestados pelo Estado a seus cidadăos: "A Estônia está cortando as ineficiências administrativas e prestando serviços integrados aos seus habitantes e empresas por meio da criaçáo de um cartāo de identificaçáo eletrônico para todos e usando um backbone de internet habilitado para o Blockchain conhecido como o "X-road", para se conectar através de vários programas e base de dados em ambos setores, público e privado. [...] Como a Estônia mostra, se nos resumimos os documentos oficiais (passaporte, certidăo de nascimento, certidăo de casamento, certidăo de óbito, carteira de motorista, cartăo de saúde, escritura de propriedades, carteira de eleitor, registro de empresas, de status de pagamentos de impostos, carteira de trabalho, histórico escolar etc.) que existem atualmente em vários bancos de dados em um único Blockchain, redes habilitadas no Blockchain poderiam entregar serviços integrados sem passar por qualquer processamento central. Esse modelo năo só poderia proteger a privacidade, como poderia melhorá-la permitindo às pessoas verificar a exatidâo de suas informaçóes, e ver quem acessou ou adicionou tal informaçấo (ou seja, uma auditoria de informaçōes permanente)." (Idem, p. 247-248).

13 É possível, por exemplo, a reuniâo de assinaturas dos cidadâos, com as respectivas datas e dados pessoais identificadores validando o número de aderentes a determinado projeto de lei de iniciativa popular a fim de certificar o quórum constitucional necessário.

14 Seria possível pensar em novos modelos de negócio como a proposta feita por Dan Tapscott e Alex Tapscott: "Nós fizemos um brainstorm com o especialista em Blockchain Dino, Mark Angaritis, para desenhar um concorrente do Airbnb no Blockchain. Nos decidimos chamar nosso novo negócio de "bAirbnb". Ele se pareceria mais com uma cooperativa de propriedade dos próprios cooperados. Todas as receitas, excluindo despesas gerais, iriam para seus membros, que controlariam a plataforma e tomariam as decisōes. bAirbnb é uma aplicaçăo distribuída (DApp), um conjunto de contratos inteligentes que armazenam dados em registros internos do Blockchain. A aplicaçăo bAirbnb possui uma interface elegante: proprietários podem enviar informaçóes e imagens de sua propriedade. A plataforma mantém pontuaçóes por reputaçāo tanto de locadores quanto de locatários para melhoras as decisóes de negócios de todos." (Idem, p. 154).

15 Além da Bitcoin, existem, por exemplo, a Ethereum, a Monero, a Dash, a Litecoin, Ripple, e muitas outras: 
Inicialmente, é disponibilizada na rede descentralizada uma quantidade determinada de criptomoedas por um processo conhecido como Initial Coin Offer - ICO onde é oferecida aos investidores uma quantidade de unidades de uma nova moeda com promessa de valorizaçấo. Com esse aporte inicial, a rede pode se desenvolver e a nova criptomoedas se consolidar. Além disso, inicialmente, é estabelecida uma quantidade fixa e máxima de criptomoedas, gerando a escassez tecnológica que assegura sua valorizaçấo econômica, gera-se assim um lastro. Entender isso é importante para a compreensăo dos itens seguintes. No caso da Bitcoin, por exemplo, foi prevista uma quantidade máxima de 21 milhóes de bitcoins, montante que será alcançado com o tempo, de forma decrescente, isto é, a cada ano săo criadas ou tecnicamente emitidas menos unidades.

Mas como sáo criadas essas unidades? Como dito acima, o blockchain se desenvolve de uma cadeia de blocos cuja informaçăo do último e novo bloco é consolidada e validada a partir de todos os dados de todos os blocos ou elos anteriores. Assim, basicamente e dentro do que parece pertinente nesse espaço, a cada criaçăo de novo elo, com a validaçăo tecnológica das informaçôes da cadeia văo surgindo as novas unidades de criptomoedas. Essa atividade de raciocínio informático que permite reconhecer as unidades de criptomoedas já existentes na rede e que permite a partir dessas a criaçâo de novas unidades dentro do limite esperado e previamente programado no início da cadeia de blocos é conhecida como mineraçâo. Também nesse processo sâo validadas as transaçôes das unidades de criptomoedas já existentes, pelo processamento matemático profundamente complexo. Uma mercadoria em si considerada. Năo há, portanto, uma autoridade central que controla a emissăo, a transferência e validaçăo das unidades (o que é uma das principais diferenças desse sistema para o sistema bancário tradicional). ${ }^{16-17}$

\section{A CARACTERIZAÇÃO DAS CRIPTOMOEDAS COMO MERCADORIA- EQUIVALENTE ESPECÍFICA NA ÓTICA DE KARL MARX: EQUIPARAÇÃO TEÓRICA AO OURO.}

Feitas as consideraçóes técnicas que se reputava imprescindíveis para compreender o surgimento e o funcionamento das criptomoedas acredita-se ter criado uma base de raciocínio para se iniciar a leitura de tal fenômeno à luz dos conceitos colocados por Karl Marx no Capítulo 3, do Livro I, de sua obra "O Capital".

\footnotetext{
"Atualmente, há uma grande quantidade de Criptomoedas em circulaçăo, cada uma delas com as suas próprias características. Dentre tais criptomoedas podemos citar a Litecoin, que conta com a vantagem de realizar transaçóes com alta velocidade, a Dogecoin que possui grande popularidade e a Novacoin.". (SILVA, 2017, p. 4).

16 "O que significa dizermos que 'a rede' verifica as transaçōes e as reconcilia com o registro público? E como exatamente sáo criados e introduzidos novos bitcoins na oferta monetária? Como vimos, porque o Bitcoin é uma rede peer-to-peer, năo há uma autoridade central encarregada nem de criar unidades monetárias nem de verificar as transaçôes. Essa rede depende dos usuários que proveem a força computacional para realizar os registros e as reconciliaçōes das transaçóes. Esses usuários sâo chamados de 'mineradores', porque săo recompensados pelo seu trabalho na medida que milhares de computadores dispersos resolvem problemas matemáticos complexos que verificam as transaçóes no blockchain." (ULRICH, 2014, p. 19).
}

17 Como coloca Luís Silva: "O Sistema Bitcoin, na condiçâo de sistema náo centralizado, impede que ingerências sobre a circulaçâo de moeda sejam realizadas." (Idem, p. 7). 
Para tanto, pretende-se desenvolver tal tarefa em dois momentos: (i) a compreensăo da teoria de Karl Marx a respeito da troca de mercadorias e da funçáo do ouro e do dinheiro como medida de valor e mercadoria-equivalente específica; e (ii) a tentativa de realizar o ajuste do fenômeno das criptomoedas à essa teoria.

\subsection{A TEORIA DE KARL MARX}

No Capítulo 3, do livro I, de sua mais conhecida obra "O Capital", Karl Marx trabalha as ideias de ouro como dinheiro e a circulaçăo de mercadorias, explicando como as relaçôes de troca se desenvolvem. Aliás, como reconhecido, a relaçâo de trocas de mercadorias é uma das grandes premissas teóricas de seu pensamento. ${ }^{18}$

Para tanto, ele trabalha com as funçôes inerentes do ouro que resultaram na compreensăo dessa mercadoria como medida universal de valores, assumindo, na sequência, padróes monetários de referência para a troca de mercadorias.

Muito bem. O ouro para Karl Marx assume duas funçōes no plano das relaçôes de troca de mercadorias. Uma primeira representada por sua própria expressâo de valor, ou seja, o ouro como mercadoria em si considerada, e uma segunda funçăo de representar os valores das mercadorias, como uma grandeza de referência que viabiliza a circulaçăo. ${ }^{19}$ No item subsequente, se verá que as criptomoedas parecem ter assumido as mesmas funçōes.

Na primeira funçăo, como mercadoria em si considerada, o ouro é nas palavras de Marx "a encarnaçấo social do trabalho humano", 20 pois, cabe a breve explicaçăo, na obra do autor, o valor da mercadoria está diretamente relacionado ao trabalho humano nela de despendido de alguma forma.

O ouro possui em si o valor como mercadoria e só por isso foi eleito historicamente como medida universal de troca de outras mercadorias. Se ninguém tivesse interesse no ouro enquanto bem si considerado em nenhum momento ele teria sido objeto de troca por qualquer mercadoria. A troca só existiu porque quem possuía a mercadoria $A$ (qualquer mercadoria) desejava a mercadoria $\mathrm{B}$ (ouro) enquanto bem em si e năo como meio de troca e, porque, o detentor da mercadoria $B$ (ouro) tinha interesse na mercadoria $A$ (qualquer mercadoria). Como diz, novamente, Marx "O ouro só pode servir como medida de valor porque ele próprio é produto do trabalho.". ${ }^{21}$

18 A própria concepçāo jurídica advinda do Marxismo se expressa com essa premissa: “É o marxismo, analisando a história de modo dialético, o responsável por revelar que modos de produçáo anteriores se valiam de aparatos de dominaçăo mais diretos e brutos. [...] O capitalismo estrutura uma instância política específica, estatal, distinta dos próprios exploradores burgueses. A circulaçāo mercantil constrói necessariamente um conjunto de instâncias de tipo jurídico, que serve de fundamento." (MASCARO, 2015, p. 61).

19 "A primeira funçâo do ouro é de fornecer ao mundo das mercadorias o material de sua expressâo de valor ou de representar os valores das mercadorias como grandezas de mesmo denominador, qualitativamente iguais e quantitativamente comparáveis. Desse modo, ele funciona como medida universal dos valores, sendo apenas por meio dessa funçâo que o ouro, a mercadoria-equivalente específica, torna-se, inicialmente dinheiro." (MARX, 2017, p. 169).

21 Idem, p. 173. 
Assim, o ouro passa a ser considerado dinheiro na medida que assume uma funçăo de intermediaçâo, por assim dizer, que viabiliza a circulaçăo de mercadorias, assumindo a condiçáo de medida universal de valor.

Explica-se. O detentor ou produtor da mercadoria $\mathrm{C}$, que tem em si o valor de trabalho que lhe confere o valor de mercadoria em si considerada, pode nâo ter interesse na troca direta pela mercadoria $\mathrm{D}$, e o inverso pode ser igualmente verdadeiro. Assim, nessas situaçôes, ambos os detentores ficariam impossibilitados de promover a circulaçáo das mercadorias, pelo desinteresse na troca direta. Ou um dos detentores recorre à violência para tomar a mercadoria do outro ${ }^{22}$ - que náo desejava a troca - ou ambos aceitam uma mercadoria que assume a funçăo de medida universal de equivalência, ou seja, que sirva de ponte sobre esse rio de desajuste de interesses. O ouro, porque tem valor em si considerado para ambos, serve de medida universal de equivalência ou de ponte.

Na leitura de Marx, a circulaçăo de mercadoria se dá na fórmula M-D-M. A mercadoria poderia ser trocada por outra mercadoria na relaçâo $\mathrm{M}-\mathrm{M}$, no entanto considerando os percalços de interesses, como dito acima, é necessária a intermediaçâo de uma medida universal de valor, no caso a mercadoria-dinheiro. Desse modo, a relaçâo de troca se dá pela dita relaçâo M-D-M ou mercadoria-dinheiro-mercadoria.

O dinheiro ou o ouro como dinheiro, portanto, assume a condiçăo de manifestaçăo externa do valor da mercadoria na relaçâo de troca. A mercadoria A tem seu valor intrínseco, mas na relaçăo de troca é preciso que ela assuma um valor extrínseco, ou seja externo. A quantidade de dinheiro paga, assim, é o reflexo do valor intrínseco da mercadoria A na relaçăo de troca. ${ }^{23}$

Esse valor em ouro equivalente à mercadoria é o que Karl Marx define como preço. Ou seja, "O preço é a denominaçâo monetária do trabalho objetivado na mercadoria. Por isso, a equivalência entre a mercadoria e a quantidade de dinheiro - cujo nome é seu

22 "As mercadorias nâo podem ir por si mesmas ao mercado e trocar-se umas pelas outras. Temos, portanto, de nos voltar para seus guardiôes, os possuidores de mercadorias. Elas sáo coisas e, por isso, náo podem impor resistência ao homem. Se náo se mostram solícitas, ele pode recorrer à violência; em outras palavras, pode tomá-las à força." (Idem, p. 159).

23 "Atéomomento, năo conhecemos nenhuma relaçáo econômica dos homens senăo aquela entre possuidores de mercadorias, uma relaçấo em que cada um só apropria produto do trabalho alheio na medida em que se despoja [entfremdet] de seu próprio produto. Por conseguinte, um possuidor de mercadoria só pode atuar como possuidor de dinheiro perante outro possuidor de mercadoria na medida em que seu produto possui, por natureza, a forma-dinheiro - e, portanto, é material dinheiro [Geldmaterial] -, ou na medida em que sua própria mercadoria muda de pele, despojando-se de sua forma de uso original. Para funcionar como dinheiro, o ouro tem, naturalmente, de ingressar no mercado em algum ponto. Tal ponto se encontra em sua fonde de produçăo, onde ele é trocado como produto direto do trabalho por outro produto do trabalho de mesmo valor. Mas, a partir desse momento, ele passa a representar preços realizados de mercadorias. Excetuando o momento da troca de ouro por mercadoria, em sua fonte de produçâo o ouro é, nas mâos de todo possuidor que alienou sua mercadoria, a figura externalizada de sua mercadoria alienada, o produto da venda ou da primeira metamorfose das mercadorias $\mathrm{M}-\mathrm{D}$. [...] O ouro tornou-se dinheiro ideal ou medida de valor porque todas as mercadorias passaram a medir seus valores por ele, convertendo-o, assim, no oposto representado de sua figura de uso, isto é, em sua figura de valor. Ele se torna dinheiro real porque as mercadorias, por meio de sua alienaçấo universal [allseitige Veräusserung], fazem dele sua figura de uso efetivamente exteriorizada ou transformada e, desse modo, sua figura de valor. Em sua figura de valor, a mercadoria se despoja de todo traço de seu valor de uso natural-espontâneo e do trabalho útil particular ao qual ela deve sua origem, a fim de se crisalidar na materialidade social e uniforme do trabalho humano indiferenciado. Náo se percebe no dinheiro de que qualidade é a mercadoria que foi nele transformada. Em sua forma dinheiro, uma mercadoria tem a mesma aparência que a outra. Por isso, o dinheiro pode ser lixo, embora lixo nâo seja dinheiro." (Idem, p. 182-183). 
preço - é uma tautologia, assim como a expressăo relativa de valor de uma mercadoria é sempre a expressăo da equivalência entre duas mercadorias.". ${ }^{24}$

\subsection{AS CRIPTOMOEDAS COMO MERCADORIA-EQUIVALENTE ESPECÍFICA}

No item precedente tentou-se, sem qualquer pretensăo de esgotar o tema, resumir a teoria de Karl Marx disposta no Capítulo 3 do Livro I de sua obra "O Capital". Feito isso, o ajuste do fenômeno das criptomoedas à referida teoria parece ter de passar por dois entendimentos: (i) se elas sâo ou năo mercadorias em si consideradas e (ii) se assumem ou năo a funçăo de medidas universais de valor. Em outras palavras, é necessário saber se as criptomoedas podem assumir as duas funçóes pelas quais Marx identifica o ouro: a funçăo de mercadoria em si considerada e a funçăo de medida universal de valor.

Se ambas respostas forem positivas parece ser possível fazer uma equiparaçâo teórica das criptomoedas com o ouro, o que, por conseguinte, viabilizaria a qualificaçăo de tais bens como mercadoria-equivalente específica.

Quanto à primeira pergunta, é preciso identificar se as criptomoedas possuem um valor intrínseco, isto é, um valor como mercadoria em si considerada, pois somente dessa forma podem assumir - ultrapassando uma primeira premissa necessária - a condiçăo de medida universal de valor na teoria de Marx, equiparando-se ao ouro nesse aspecto. A resposta parece ser afirmativa por três razōes: o chamado procedimento de mineraçấo; o fato das criptomoedas, independentemente de sua natureza, serem inegável objeto de investimento; e a existência de escassez criada de forma artificial e informática.

É por meio do procedimento de mineraçăo que as criptomoedas sâo geradas. Como visto no item 1 desse trabalho, a cada criaçấo de novo elo no blockchain, com a validaçáo tecnológica das informaçôes da cadeia vâo surgindo as novas unidades de criptomoedas. É feito um raciocínio informático que permite reconhecer as unidades de criptomoedas já existentes na rede e que permite, a partir dessas, a criaçăo de novas unidades dentro do limite esperado e previamente programado no início da cadeia de blocos. ${ }^{25}$

Nâo se trata, de um procedimento simples, mas de contas matemáticas extremamente complexas que dependem de esforços humanos, estruturais e principalmente de grande capacidade computacional e gasto de energia elétrica. ${ }^{26}$ Para ilustrar, basta dizer que na Islândia, por exemplo, o gasto de energia na mineraçăo de criptomoedas

24 Idem, p. 176.

25 Ver nota 15.

26 "As miners update the block chain, their computational efforts carry significant costs. In particular, the computerized proof-of-work calculations are quite power-intensive, consuming more than 173 megawatts of electricity continuously. For perspective, that amount is approximately 20 percent of an average nuclear power plant (World Nuclear Association 2015), or approximately $\$ 178$ million per year at average US residential electricity prices. These computational costs have grown sharply and may rise further because Bitcoin automatically adjusts puzzle difficulty so that the time interval between two blocks remains roughly tem minutes. As more computing power joins the Bitcoin system, the puzzles automatically become more difficult, increasing computing and electricity requirements. In fact, an arms race ensued as the price of bitcoin rose. Taylor (2013) compares the difficulty of solving the puzzle to the bitcoin-dollar exchange rate, finding that spikes in the exchange rate-bitcoins becoming more valuable in terms of US dollars - have been followed by increases in computational difficulty." (BOHME, Idem, p. 218. 
já ultrapassou o consumo de energia doméstica. ${ }^{27} \mathrm{O}$ gasto de energia é tamanho que, inclusive, há grande preocupaçâo com os prejuízos ambientais decorrentes de tal atividade. ${ }^{28}$ Em contrapartida e como forma de incentivo para que os usuários resolvam esses quebra-cabeças matemáticos, esses săo recompensados com unidades de criptomoedas recém-criadas. Fato é que, nesse cenário, parece impossível considerar que a atividade de produçáo de criptomoedas náo apresenta valor em si agregado de modo que elas podem ser consideradas, em uma leitura contemporânea na conceituaçăo de Marx, como mercadoria.

Em segundo lugar, tem-se nas criptomoedas verdadeiro objeto de investimento. Independentemente de qual for sua natureza jurídica, fato é que as criptomoedas tem sido alvo de direcionamento de grandes quantias financeiras por quem deseja o lucro a partir da valorizaçăo de tais bens. No Brasil, neste ano, v.g., o número de investidores em Bitcoin atingiu mais que o dobro de investidores da bolsa no país e ainda superou o número de investidores em ativos nas letras de título do tesouro nacional (GOMES; LAPORTA, 2018)

Em terceiro, só parece ser possível ter valor aquilo que tem uma quantidade limitada, aquilo que é escasso. Do contrário, năo é possível falar em algo criado mediante valor de trabalho humano agregado, pois, se existe de forma infinita por natureza, năo faz sentido falar em criaçăo mediante trabalho despendido, faltando o valor como mercadoria conforme definido na teoria de Marx. Em outras palavras, a escassez artificialmente criada permite que as criptomoedas sejam mercadorias em si consideradas pois dotadas de valor - mediante o estabelecimento inicial de uma quantidade máxima, de modo que nenhuma criptomoeda será criada no blockchain se năo respeitar a quantia preestabelecida.

Ultrapassada essa primeira fase e observando que as criptomoedas podem ser consideradas sim como mercadorias, passa-se à segunda fase do raciocínio entender se assumem ou năo a funçấo de medidas universais de valor. A resposta também parece afirmativa.

Tem-se observado contemporaneamente a aceitaçăo das criptomoedas como meios de pagamento, ou seja, tem-se operado com as criptomoedas aquela fórmula M-D-M identificada por Marx, o que aqui se identifica e se propóe como fórmula M-C-M, onde há a relaçâo de troca de mercadorias da seguinte ordem: mercadoria-criptomoeda-mercadoria. Vamos aos exemplos.

27 "The success of cryptocurrencies around the globe has had a more unexpected repercussion on the island of 340,000 people: As Iceland has become one of the world's prime locations for energy-hungry cryptocurrency servers - something analysts describe as a 21st-century gold-rush equivalent the industry's electricity demands have skyrocketed, too. For the first time, they may now exceed Icelanders' own private energy consumption, and some energy producers fear that they won't be able to keep up with rising demand if Iceland continues to attract new companies bidding on the success of cryptocurrencies.". (NOACK, 2018)

28 "In November, the power consumed by the entire bitcoin network was estimated to be higher than that of the Republic of Ireland. Since then, its demands have only grown. It's now on pace to use just over $42 \mathrm{TWh}$ of electricity in a year, placing it ahead of New Zealand and Hungary and just behind Peru, according to estimates from Digiconomist. That's commensurate with $\mathrm{CO} 2$ emissions of 20 megatonnes - or roughly $1 \mathrm{~m}$ transatlantic flights. That fact should be a grave notion to anyone who hopes for the cryptocurrency to grow further in stature and enter widespread usage. But even more alarming is that things could get much, much worse, helping to increase climate change in the process.". (HERN, 2018). 
Noticiou-se, recentemente, por exemplo, que empresas como Overstock, Expedia, Subway, PayPal, Shopify e Pizzaforcoins aceitam o pagamento de seus bens e serviços em criptomoedas.

Também, a empresa de alimentaçăo KFC Canadá anunciou a aceitaçăo de pagamento em Bitcoin para um de seus produtos (HIGGINS, 2018). A Microsoft aceita que os usuários comprem conteúdo para download na sua plataforma de games Xbox ou na Windows Store mediante o pagamento em bitcoins (VANIAN, 2018). Igualmente, a companhia aérea Surf Air passou a aceitar o pagamento em bitcoins e ethereum ${ }^{29}$, da mesma forma o Grupo Reserva de vestuário ${ }^{30}$. Parece ser um caminho sem volta, o número de outros exemplos é significante.

Feitas essas consideraçôes, parece ser possível concluir pelo ajuste das criptomoedas no conceito de Karl Marx como mercadoria-equivalente específica. Segundo o autor:

A primeira funçấo do ouro é de fornecer ao mundo das mercadorias o material de sua expressăo de valor ou de representar os valores das mercadorias como grandezas de mesmo denominador, qualitativamente iguais e quantitativamente comparáveis. Desse modo, ele funciona como medida universal dos valores, sendo apenas por meio dessa funçáo que o ouro, a mercadoria-equivalente específica, torna-se, inicialmente dinheiro. ${ }^{31}$

O ajuste se dá pois, assim como o ouro, as criptomoedas possuem valor enquanto mercadorias em si consideradas, o que na leitura de Marx é um atributo primordial para que possa servir de meio intermediário de trocas de mercadoria. Supera-se, portanto, essa premissa conceitual. Mas năo só, como visto, as criptomoedas, justamente por terem valor em si, têm assumido essa funçăo de meio intermediário de trocas, na fórmula mercadoria-criptomoeda-mercadoria em aparente identidade conceitual à fórmula proposta no Capítulo 3 do Livro I da obra "O Capital" mercadoria-dinheiro-mercadoria.

Em conclusăo, as criptomoedas podem ser consideradas como medidas universais dos valores, como a mercadoria-equivalente específica.

\section{CONCLUSÃO}

Concluindo o ensaio, parece possível, sem a pretensâo de esgotar o tema, mas também sem medo de errar, que o fenômeno das criptomoedas pode sim ser lido a partir da obra "O Capital" de Karl Marx, principalmente a partir dos conceitos por ele desenvolvidos no Capítulo 3 do Livro I dessa obra, onde ele discute o ouro, o dinheiro e a circulaçăo de mercadorias.

Ali, o autor identifica duas funçôes do ouro no plano das relaçōes de troca de mercadorias: uma primeira representada por sua própria expressăo de valor, ou seja,

29 CISION PR NEWSWIRE. Disponível em: https://www.prnewswire.com/news-releases/silicon-valley-airtravel-provider-surf-air-now-accepting-payment-via-bitcoin-and-ethereum-300563833.html. Acesso em: 15.04.2018.

30 DCI - DIÁRIO COMÉRCIO INDÚSTRIA E SERVIÇOS. Disponível em: https://www.dci.com.br/comercio/ reserva-passa-a-aceitar-bitcoin-1.674931. Acesso em: 15.04.2018.

31 Idem, p. 169. 
o ouro como mercadoria em si considerada, e uma segunda funçăo de representar os valores das mercadorias, como uma grandeza de referência que viabiliza a circulaçâo.

O ouro possui em si o valor como mercadoria e só por isso foi eleito historicamente como medida universal de troca de outras mercadorias. Se ninguém tivesse interesse no ouro enquanto bem si considerado em nenhum momento ele teria sido objeto de troca por qualquer mercadoria. Nesse passo, assume a condiçăo de dinheiro e de manifestaçăo externa do valor da mercadoria na relaçâo de troca, na fórmula mercadoria-dinheiro-mercadoria (M-D-M). Viabiliza, portanto, a circulaçâo de mercadorias.

Foi possível entâo traçar um paralelo entre essa leitura sobre o ouro como dinheiro feita por Marx e o fenômeno das criptomoedas na dinâmica que assumem na contemporaneidade. Isso porque as criptomoedas também agregam essa dupla funçâo identificada pelo autor. Săo mercadorias em si consideradas, sobretudo considerando o procedimento de mineraçáo, o fato de que sáo objeto de investimento e a existência de escassez criada de forma artificial e informática. E, por que assim o sâo, tem sido aceitas como meio de pagamento, podendo ser consideradas como mercadoria-equivalente específica, ficando a proposta pela configuraçăo de uma fórmula mercadoria-criptomoeda-mercadoria (M-C-M). 


\section{REFERÊNCIAS}

ALBUQUERQUE, Bruno Saboia de; CALLADO, Marcelo de Castro. Understanding Bitcoins: Facts and Questions. Revista Brasileira de Economia, v. 69, n. 1, p.3-16, 2015.

BÖHME, Rainer et al. Bitcoin: Economics, Technology, and Governance. Journal Of Economic Perspectives, v. 29, n. 2, p. 213-238, Maio.2015.

BRASIL. Lei no 13.105 de 16 de março de 2015. Disponível em: http://www.planalto.gov.br/ccivil_03/_ato2015-2018/2015/lei/113105.htm. Acesso em: 03.07.2018.

CISION PR NEWSWIRE. Disponível em: https://www.prnewswire.com/news-releases/silicon-valley-air-travel-provider-surf-air-now-accepting-payment-via-bitcoin-and-ethereum-300563833.html. Acesso em: 15.04.2018.

DCI - DIÁRIO COMÉRCIO INDÚSTRIA E SERVIÇOS. Disponível em: https://www. dci.com.br/comercio/reserva-passa-a-aceitar-bitcoin-1.674931. Acesso em: 15.04.2018.

GOMES, Helton Simōes; LAPORTA, Taís. Bitcoin já tem mais que o dobro de investidores da bolsa no Brasil. 2018. Disponível em: https://g1.globo.com/economia/ educacao-financeira/noticia/bitcoin-ja-tem-mais-que-o-dobro-de-investidores-da-bolsa-no-brasil.ghtml. Acesso em: 20.01.2018.

HERN, Alex. Bitcoin's energy usage is huge - we can't afford to ignore it. 2018. Disponível em: https://www.theguardian.com/technology/2018/jan/17/bitcoin-electricity-usage-huge-climate-cryptocurrency. Acesso em: 17.01.2018.

HIGGINS, Stan. KFC Canada Is Accepting Bitcoin for Fried Chicken. 2018. Disponível em: https://www.coindesk.com/kfc-canada-is-accepting-bitcoin-for-fried-chicken/. Acesso em: 12.01.2018.

MARX, Karl. O capital : crítica da economia política : livro I : o processo de produçâo do capital; Traduçăo de Rubens Enderle, 2. Ed, Sáo Paulo : Boitempo, 2017.

MASCARO, Alysson Leandro. Introduçâo ao Estudo do Direito, 5. Ed., Săo Paulo : Atlas, 2015.

NOACK, Rick. Cryptocurrency mining in Iceland is using so much energy, the electricity may run out. 2018. Disponível em: https:/www.washingtonpost.com/news/ worldviews/wp/2018/02/13/cryptocurrency-mining-in-iceland-is-using-so-much-energy-the-electricity-may-run-out/?utm term=.edd7078053df. Acesso em: 13.02.2018. 
SILVA, Luis Gustavo Doles. A regulaçâo do uso de criptomoedas no Brasil. 2017. 123 f. Dissertaçăo (Mestrado) - Curso de Direito Político e Econômico, Universidade Presbiteriana Mackenzie, São Paulo, 2017.

SWAN, Melanie. Blockchain. Sebastopol : O'Reilly Media, Inc., 2015.

TAPSCOTT, Don. TAPSCOTT, Alex. Blockchain revolution : como a tecnologia por trás do Bitcoin está mudando o dinheiro, os negócios e o mundo, Săo Paulo : SENAISP Editora, 2016.

ULRICH, Fernando. Bitcoin: a moeda na era digital, Săo Paulo : Instituto Ludwig Von Mises Brasil, 2014.

VAINZOF, Rony. Responsabilidade por danos decorrentes de conteúdos gerado por terceiros In DEL MASSO, Fabiano. ABRUSIO, Juliana. FLORÊNCIO FILHO, Marco Aurélio [coord.] Marco Civil da Internet Lei 12.965/2014, Săo Paulo : RT, 2014.

VANIAN, Jonathan. Microsoft Welcomes Back Bitcoin. Disponível em: http://fortune. com/2018/01/10/microsoft-bitcoin-temporary-halt/. Acesso em: 10.01.2018. 